\title{
SGP-Frühjahrssymposium, Kongresshaus Aarau, 08.05.2021 (hybrid)
}

Am 08.05.2021 findet in Aarau das SGPFrühjahrssymposium als Hybridveranstaltung statt.

Einerseits dient die Veranstaltung als Vorbereitung für junge Phlebologinnen und Phlebologen im Hinblick auf die Prüfung zum Fähigkeitsausweis in Phlebologie.

Ferner können Kandidatinnen und Kandidaten für den Fähigkeitsausweis in endovenöser Thermoablation hier den obligatori- schen 8-stündigen klinischen PhlebologieKurs absolvieren.

Last not least ist sie aber auch ein optimales Update für gestandene Fachärztinnen und Fachärzte, die bereits im Besitz ihres Facharztdiploms und ihrer Fähigkeitsausweise sind.

Wir werden die Hybridveranstaltung am Kongresshaus Aarau, geografisch ungefähr in der Mitte der Schweiz, durchführen. So- wohl Teilnehmerinnen und Teilnehmer als auch Referentinnen und Referenten können frei auswählen, ob sie die Tagung als Präsenzveranstaltung oder online besuchen möchten. Alle Präsenzteilnehmer erhalten unentgeltlich einen Corona-Schnelltest und während der ganzen Veranstaltung müssen FFP2-Masken getragen werden, welche zur Verfügung stehen. 